\author{
REVIEW OF EUROPEAN AND COMPARATIVE LAW \\ VOLUME XLVI \\ YEAR 2021, ISSUE 3, pp. 27-42 \\ DOI: https://doi.org/10.31743/recl.12432
}

\title{
THE RIGHT TO BE FORGOTTEN: EMERGING LEGAL ISSUES
}

\author{
Oksana V. Kiriiak*
}

\begin{abstract}
This paper contextualizes and analyzes the main emerging approaches to the understanding of the right to be forgotten and its application in praxis, using legislation and judicial practice of the European Union and Ukraine as reference scales. By bridging the gap between positive and interpretative orders of law implementation, which were previously imperatively opposed and considered mutually exclusive in the Ukrainian legal system, the paper supports the arguments that the process of mastering the protection of right to be forgotten requires a further mindset shift equally for-Internet providers and all involved law enforcers.
\end{abstract}

Keywords: right to be forgotten, right to remember, court jurisdiction, trials, human rights and freedoms

\section{INTRODUCTION}

At the present stage of sociolegal development, the concept of the need to establish high standards in the sphere of legal status of a person and the consolidation of individual non-property rights is becoming increasingly important. At the same time, the juridification of basic right to be forgotten (hereinafter - RTBF) has caused the emergence of a long-stand-

\footnotetext{
Dr. Oksana V. Kiriiak, Associate Professor, Yuriy Fedkovych Chernivtsi National University; correspondence address: Kotsyubynsky 2, Chernivtsi, 58012, Ukraine; e-mail: o.kiriyak@chnu.edu.ua; https://orcid.org/0000-0001-8850-805X.
} 
ing controversy in the scientific sphere, the determinant of which is the lack of theoretical understanding of these values from a legal point of view, which imposes its impact on the normative regulation of the studied matter. Thus, we reach now to Carsten M. Wulff's (2020) idea, the element of time is highlighted as an element introduced in the balancing of competing rights which was not directly foreseen by the legislators in different countries ${ }^{1}$.

Over the past few years, based on the research, conducted by Federico Fabbrini, and Edoardo Celeste (2020), the European framework for data protection has progressively extended its reach outside the jurisdiction of the EU. On the one hand, the European Court of Justice (hereby - ECJ) has reviewed the standard of data protection existing in third countries to decide whether this was sufficient to authorize the transfer of personal data from the EU to such third country - essentially pressuring the latter to raise its domestic standards to meet the EU benchmark ${ }^{2}$. But on another hand, the question of their legislative implementation to the legal system of various countries raises many empirical and conceptual difficulties, which we will consider in this article through the Ukrainian mirror. Moreover, such a wide palette of views of representatives of various scientific schools leads to the fact that the RTBF is understood as a separate sphere of legal regulation alien to national legislation, which due to many interrelated reasons objectively cannot be applied to the Ukrainian realities for different reasons.

In the system of Ukrainian legislation, there is still no single act regulating the application of RTBF, the key definition of this concept has not been defined yet, a bunch of legal norms has not been developed for procedural algorithms for the implementation of this legal structure in practice. All this requires from the legislator is a comprehensive study and in-depth research of the factors affecting the possibility of its application to specific categories, as well as determining the prospects for the development of this legal institution. Therefore, this correlates with the generalizing conclu-

1 Carsten M. Wulff, "The Right to be Forgotten in Post-Google Spain Case Law: an Example of Legal Interpretivism in Action?," Comparative Law Review 26 (2020): 259.

2 Federico Fabbrini and Edoardo Celeste, "The Right to Be Forgotten in the Digital Age: The Challenges of Data Protection Beyond Borders," German Law Journal 21 (2020): 60. 
sions of Cayce Myers (2014), who reasonably asserts that the RTBF illustrates a tension in the concept of the contours of public and private space within the realm of social media, international transactions, and the new digital age in different countries ${ }^{3}$.

Interoperability of several trends in the complex perception of the right under study is quite a complex process, and it should be considered taking into account the methodological techniques of system analysis and comparative law, consistently comparing those factors that made it possible to use the RTBF in the territory of the European Union and determine the need to apply it in Ukraine.

\section{ERASION OF DIGITAL MEMORY}

The institute of human rights and freedoms represents one of the most significant outcomes of the legal progression of society, from ancient times to the present day, when human rights have become an indispensable attribute of a democratic state governed by the rule of law. That is why it is reasonable that with the advancement of social order and the widespread introduction of leading-edge digital technologies into our lives, increasingly new types of rights, as well as forms of their implementation, appear, which could not even be imagined half a century ago. In addition to the very unprecedented development in mass culture of various digital forms of interaction, due to the fundamentally new quality and scale of technologies, there are more and more situations in everyday life that can be considered controversial in the light of possible law enforcement. Among other things, this problem is intensifying with legal restrictions and rules for the dissemination of information emerge, which, in turn, is due to the development of concepts of state sovereignty and its extension to the information space.

Conceivably, it was Vladimir Jankélévitch (2005) who would have us believe that it is possible to live without remembering, but impossible to

3 Cayce Myers, "Digital Immortality vs. "The Right to be Forgotten": A Comparison of U.S. and E.U. Laws Concerning Social Media Privacy," Revista Română de Comunicare şi Relatiii Publice, no. 3XVI (2014): 48. 
live without forgetting: being able to trace the past, enables society to forgive what happened in the past ${ }^{4}$. This considerations echoes the Viktor Mayer-Schönberger (2011) statements: "as remembering has become the new standard, it has created opposite needs for memory, namely, to be forgotten."5. As Chanhee Kwak et al. (2021) emphasize, the general capacity of human memory has dramatically increased with the help of information and communication technologies. People hardly forget the moments of their lives that are recorded and stored digitally, thereby shifting the perception of memory from being volatile to durable ${ }^{6}$.

This finding substantiates Cayce Myers (2014) observations concerning the problem that unlike previous eras in which a person's past was relegated to a few photographs, a diary, or fading memories of those left behind, today the digital sphere provides a type of immortality within the Internet ${ }^{7}$. Turning to some of the literature in this area, Meg Leta Jones (2018) pointed out that the web has become a searchable and crunchable database for questions of any kind, a living cultural memory whose implications are complex and wide reaching ${ }^{8}$. This is directionally consistent with the findings of Viktor Mayer-Schönberger (2011), according to which the digitalization and disclosure of life's personal details "will forever tether us to all our past actions, making it impossible, in practice, to escape them."

The very idea that each individual wants certain information about him to be removed from the information space is quite natural, and, without exaggeration, understandable. However, to implement it in a socie-

4 Vladimir Jankélévitch, Forgiveness (Chicago: University of Chicago Press, 2005), 27.

5 Viktor Mayer-Schönberger, Delete: The virtue offorgetting in the digital age (Princeton: Princeton University Press, 2011), 165.

6 Chanhee Kwak, Lee Junyeong, and Lee Heeseok, "Could You Ever Forget Me? Why People Want to be Forgotten Online," Journal of Business Ethics 168, Issue 5 (2021), https:// www.scopus.com/record/display.uri?eid=2-s2.0-85100146466\&origin=resultslist\&sort=plf -f\&src=s\&st $1=\& s t 2=\&$ sid $=0$ daeb36f35186b6eecf36fa91bb91586\&sot $=b \& s d t=b \& s l=36 \& s$ =TITLE-ABS-KEY\%28right+to+be+forgotten\%29\&relpos=3\&citeCnt=0\&searchTerm=.

Myers, "Digital Immortality vs. "The Right to be Forgotten", 48.

8 Meg Leta Jones, Ctrl + Z: The Right to Be Forgotten (New York: New York University Press, 2018), 5.

9 Mayer-Schönberger, Delete: The virtue of forgetting in the digital age, 163-164. 
ty that declares openness and freedom of speech is not an easy task. We need to agree with Rebekah Larsen (2020), who conveyed that notably, in the eyes of the law, the RTBF is not an absolute right; it must always be balanced against "other fundamental rights," including freedom of expression, as a crucial public interest safeguard ${ }^{10}$.

Meanwhile, it is obvious that the time has come not to oppose human rights and positive law, but to consider them in dialectical unity as parts of a unified entity. It is thought that only a modern normative legal understanding can remove the existing contradictions between the "newest" and traditional normative legal understanding, change the attitude of law enforcers to the category "human rights" not as an ideological stamp, but as a really existing legal phenomenon. This, in turn, actualizes the consideration of human rights as a legal structure that requires proper interpretation as a prerequisite for optimal law enforcement in the future.

An excellent platform for testing the hypothesis of interaction with digital memory is precisely the RTBF, which has not yet become routine for the Ukrainian legal system and therefore undergoes all the stages of positive legal perception in conjunction with the use of interpretative tools and emerging approaches to its understanding.

\section{EMERGING APPROACHES TO THE RTBF}

The pluralism of approaches to RTBF, the variety of models of its understanding are quite adequate to the modern development of the humanities and are not a sign of crisis in jurisprudence. To date, legal science has not achieved even a rough convergence of views among world-wide scholars as to what is to be regarded as an RTBF. This leads to the absence of a well-considered and balanced legal policy, but is able to explain why several views of this problem are now confronting one another. This was predicated on assumptions of the pluralistic, "democratic" nature of such

10 Rebekah Larsen, "Mapping Right to be Forgotten frames: Reflexivity and empirical payoffs at the intersection of network discourse and mixed network methods," New media \& society 22(7) (2020): 1246. 
information networks and the comprehensive nature of network methods (Rebekah Larsen, 2020) ${ }^{11}$.

I. Among the most common approaches to the question under study at the current stage of development of legislative practice, in our view, the following definitional turns should be correlated:

1) a right to removal (Selen Uncular, 2019) ${ }^{12}$,

2) a right to suppression (Christopher Kuner, 2015) ${ }^{13}$,

3) a right of oblivion (Cayce Myers, 2014) ${ }^{14}$.

Given the content of the above-mentioned definitions, we believe that there are no grounds for opposing them, because they are more likely to complement one another and allow to use different views to investigate the same problem. Moreover, all proponents of the extended use of this legal construct are one in the same, RTBF as a chance for an individual to be relieved of his or her past and be able to start with a clean bill ${ }^{15}$. In the opposite case, ignoring any of the previously described components deprives the integrity of the whole picture of the existence of the right in question. As Mattias Goldmann (2020) deplores, the RTBF is relevant on many levels and only taking them together, the double decision appears as an ingenious move ${ }^{16}$.

Notably, in the eyes of the law, once again, the RTBF is not an absolute right; it must always be balanced against "other fundamental rights." 17. But the possibility of limiting rights and freedoms is currently a norma-

11 Larsen, "Mapping Right to be Forgotten frames," 1247.

12 Selen Uncular, "The right to removal in the time of post-Google Spain: myth or reality under general data protection regulation?," International Review of Law, Computers \& Technology 33 (3) (2019): 310.

13 Christopher Kuner, "The Court of Justice of the EU Judgment on Data Protection and Internet Search Engines," LSE Law, Society and Economy Working Papers 3 (2015): 7, https://papers.ssrn.com/sol3/papers.cfm?abstract_id=2496060, accessed February 14, 2020.

14 Myers, "Digital Immortality vs. "The Right to be Forgotten"," 48.

15 Ugo Pagallo and Massimo Durante, "Legal Memories and the Right to be Forgotten," in Protection of Information and the Right to Privacy - A New Equilibrium?, ed. Luciano Floridi (Oxford: Springer, 2014), 19.

16 Mattias Goldmann, "As Darkness Deepens: The Right to be Forgotten in the Context of Authoritarian Constitutionalism,” German Law Journal 21 (2020): 53.

17 Larsen, "Mapping Right to be Forgotten frames," 1246. 
tive concept recognised by international law (Robert Tabaszewski, 2020) ${ }^{18}$. Moreover, according to the conclusions of Kinga Machowicz (2021), the concept of the respect for/observance of human rights began to be combined with business ethics, the idea of corporate social responsibility, when it was found that the so-called wild capitalism is not the right means to develop entrepreneurship and does not thereby achieve economic well-being $^{19}$. However, the scope of EU data protection law in general - and of the right to be forgotten in particular - has been increasingly facing a question of jurisdictional boundaries, as it was pointed out by Federico Fabbrini and Edoardo Celeste (2020) ${ }^{20}$.

As Jennifer Daskal (2018) has pointed out, there are now an increasing number of cases adjudicated by courts world-wide which raised "critically important questions about the appropriate scope of global injunctions, the future of free speech on the internet and the prospect for harmonization (or not) of rules regulating online content across borders" ${ }^{21}$. These allegations cannot be considered completely unfounded, because until recently domestic jurisprudence, if it mentioned forgetting in the texts of judicial acts, only in the context of a certain loss or neglect, which ultimately fluctuated within banal human forgetfulness (forgetting one's name, forgetting to put a seal, forgetting about a promissory note, etc.) or grammatical mistakes or typos (for example, forgetting a court decision of legal force (instead of coming into force), which of course does not honor the thorough preparation of court decisions and rulings) and even the village of Zabuttya (Oblivion in Ukr.) in Khmelnytsky region. And here we can ascertain the existence of a global problem situation, which Mattias Goldmann (2020) aptly described, noting that the cases

18 Robert Tabaszewski, "The Permissibility of Limiting Rights and Freedoms in the European and National Legal System due to the Health Protection," Review of European and Comparative Law 42, no. 3 (2020): 54.

19 Kinga Machowicz, "Observance of human rights as an element of shaping the position of the European enterprise in the knowledge-based economy," Review of European and Comparative Law 44, no. 1 (2021): 16.

20 Fabbrini and Celeste, "The Right to Be Forgotten in the Digital Age," 56.

21 Jennifer Daskal, “Google, Inc v. Equustek Solutions," American Journal of International Law 112, Issue 4 (2018): 730. 
decided by the CJEU over the last couple of years only constitute the tip of the iceberg ${ }^{22}$.

Instead, there are recent grounds for using the terminology "RTBF" not only in the context of comparative law and other scientific and theoretical research, but also in the literal sense enshrined in the EU Directives. In particular, appealing to the Desniansky District Court of Chernihiv in May 2018 (case № 750/5021/18, proceedings № 4-s/750/45/18 23) with a complaint against the actions and inaction of the chief state executor of the Central Department of the State Executive Service of the city Chernihiv of the Main Territorial Department of Justice in the Chernihiv region, PERSON_1 separately expressed a requirement to apply when considering the complaint "RTBF", which is set out in Art. 17 of the General Data Protection Regulation of the European Union. Obviously, this is only a small fraction of the entire potential array of judicial appeals on the issue of implementing the RTBF in Ukrainian realities, and an unprecedented consensus among all stakeholders is reached on this issue.

The difference in research interpretations concerning the nature of RTBF counterbalances the unity of opinion of representatives of the state authorities, who adhere to the obsolescent standards in assessing social phenomena, including the digital sphere. Meanwhile, post-Soviet legal thinking and legal understanding are not always receptive to the peculiarities of the legal culture of Ukrainian society and the scientific specificity of the country. At the same time, Jure Globocnik's argumentative inferences (2020) are also worth supporting in the area of academic scholarship research because they confirm that the decisions demonstrate yet again how difficult it is to draw lines involving the internet and will have significant implications not only for internet users, but especially for tech companies in and outside the EU, as many aspects of the judgments directly affect their business models. Furthermore, as the Court is a pioneer when it

22 Goldmann, "As Darkness Deepens," 46.

23 Desniansky District Court of Chernihiv, Judgment of 25 May 2018, https:// reyestr.court.gov.ua/Review/74269229, accessed March 31, 2021. 
comes to the right to be forgotten, the decision might also indirectly affect legislation and court decisions in non-EU States ${ }^{24}$.

But the greatest legal inconsistency, however, is not even when a court refuses to grant a petitioner's RTBF claim, but when such a decision contains a verdict positive for the applicant. The text of the judgment usually contains in the public domain full information about the parties to the case and details, the removal of which after some time may be initiated by a party to the conflict, and, accordingly, will continue to be publicly available to an uncertain circle of respondents using online registries of judicial acts. These texts are at least a part of the training process, are massively studied in educational institutions of different levels, and are the subject of dissertation surveys, continue to be replicated by other courts, appear on the pages of newspapers and other periodicals, and are finally discussed by all segments of the population under different views for a certain period of time.

This has the exact opposite effect - information, the destruction of which from the online space was the main purpose of the applicant's lawsuit, continues to spread online, engraving this information for decades to come in free access for an unlimited number of people. And even if you make appropriate editorial amendments to the text of regulations and imperatively state that the consideration of this category of cases should take place only in closed court, which will necessitate the secrecy, respectively, and the content of the judgment, it is still not will ultimately prevent access to information that should be removed during the exercise of the right to forget, because for users outside the EU, all this data will remain open in the web portal of the original source, not to mention that layered users can use VPN or other resources to hide their true location by changing the IP address and otherwise.

A certain paradox can be consistently traced in all cases of this category, which is particularly emphasized by Jure Globocnik (2020), who justifiably emphasized the following: "Here, it is usually referred to as the right to de-referencing. Based on grounds relating to her particular

24 Jure Globocnik, "The Right to Be Forgotten is Taking Shape: CJEU Judgments in GC and Others (C-136/17) and Google v CNIL (C-507/17)," GRUR International 69(4) (2020): 388. 
situation, a data subject can request a search engine operator to remove (de-reference) from search results links leading to websites containing personal data pertaining to her, e.g. if the data are inadequate, irrelevant or no longer relevant in the light of the purposes for which they were collected and processed. It is important to note that this only holds true for searches conducted using her name, whereas such links can still be displayed if the search is conducted using other search terms. Furthermore, the display of a link in search results has to be considered separately from the initial publication of information. The data subject is not required to exercise her right to be forgotten with regard to both of them. Similarly, even if information is de-referenced from search results, it will still be visible on the webpage where it was initially published, save the data subject successfully invokes her right to erasure vis-a'-vis the publisher of that webpage as well" 25 .

A minor, but no less important addition to all of the above, in our view, should also be a revision of the procedural rules applied in this category of trials. As the arbiter of a wide variety of disputes, the Judge is forced to balance the interests of the parties to the process, who oppose excessive publicity of their problems, and those of society, which seeks to control the impartiality of judges. It seems possible to solve this problem only at the level of fixing the possibility to extend the regime of a closed court session and, accordingly, a secret court decision to all judicial acts, which are related to the issue of implementation of the PRR, both in online format and in paper-based proceedings. Thus, of course, the removal from the Internet will significantly limit the range of potential recipients of relevant information by residents of the European Union, while from other parts of the globe access to this information will remain open.

II. At the same time, there is a strong tendency to downgraded the importance of an adequate response of the relevant authorities to resolve issues related to the use of the legal construct of RTBF in relation to specific life situations and disputed legal relations. Unfortunately, the scientific and theoretical findings of the opponents of existence and, consequently, the practical implementation of the RTBF are used in this case as a legal

25 Globocnik, "The Right to Be Forgotten is Taking Shape," 380. 
basis for refusing to satisfy the claims of the plaintiffs, which are fully within the framework of the legal conditions of RTBF application under study.

Expiration of time in the described situations has been leading to what Jeffrey Rosen (2012) famously called the unfortunate misunderstanding; because Google Spain never established a 'new' right, it merely clarified the scope of the right to erasure. Advocates of this school of thought believe that the implementation of an actual RTBF would pose a serious threat to freedom of expression ${ }^{26}$. The above-mentioned inferences are continued to be developed by Emily Adams Shoor (2014), who maintains that the results of the downsides of mass implementation of RTBF would outweigh the benefits of its results ${ }^{27}$. Moreover, the German association of Internet economy argued that the same standards should apply for online and offline publication ${ }^{28}$.

This reasoning also does not lack rationality for the following reasons. Speaking of removing information from columns, for example, online periodicals, we should not forget that the dissemination of similar information can occur in traditional print, the entire circulation of which should also be covered by a court decision, which is practically impossible to implement. In particular, if we simulate a situation where one piece of information was published simultaneously in electronic and paper form, for example, on the pages of one publication, combining publishing activities online and offline, the legislator must demonstrate consistency in the implementation of the issue. In other words, the removal of the possibility of finding this information on personal data from the world-wide web through search engines should logically follow the order to destroy the same data from the entire circulation of printed copies, which in principle is impossible, at least for the reasons that over time, it is physically impossible to identify all, without exception, the holders of this issue of a newspaper or magazine. It is also difficult to imagine the staff involved in such a court deci-

26 Jeffrey Rosen, "The Right to Be Forgotten," Stanford Law Review, Symposium Issue (2012): 88-95.

27 Emily Adams Shoor, "Narrowing the Right to Be Forgotten: Why the European Union Needs to Amend the Proposed Data Protection Regulation," Brooklyn Journal of International Law 39 (2014): 487-521.

28 Bundesverfassungsgericht, Recht of freie Entfaltung der Persönlichkeit. 1 (BvR 16/13), 19. 
sion and the process of information retrieval. And in this case, the removal of all copies from the libraries or shelves of periodicals will still not lead to a complete and final "erasure" of information in the material world. In such a case, it is impossible to achieve the aim pursued by the applicant by applying to the court with reference to his right to be forgotten with the utmost diligence and caution. Thus, if we model the development of circumstances in this situation as far as possible, the next "logical" step would be to erase the memory of all people who have already read these sheets and can potentially disseminate them (until they receive a restraining order), thereby performing the functions of information carriers. As we see, constructing a potentially possible variant of events we can surpass ourselves and reach absurd utopias which will have no practical value, to say nothing of expediency and possibility of realization.

These related discourses create a setting and script for RTBF developments and framings. They affect which perspectives are visible. They contribute to reproducing existing inequalities via knowledge construction in a "network society." If researchers approach networks as de facto pluralistic, comprehensive representations of the social, then less visible, less powerful perspectives can become even less visible and powerful (Rebekah Larsen, 2020) ${ }^{29}$.

III. There is also a third group of researchers, whose representatives are cautious about the changes introduced by the RTBF into the familiar use of information resources, and while not directly refuting the possibility of applying this right, at the same time they do not actively advocate the fairness of its existence in general. For example, there is a certain amount of scholarly interest in David Erdos'statement (2021), which alleges that data protection can and should enable individuals to exert some control at least ex post over online data dissemination. ${ }^{30}$ Introduced by the European Union (EU), the RTBF is one such example. In Article 17, the General

29 Larsen, "Mapping Right to be Forgotten frames," 1250.

30 David Erdos, "The right to be forgotten' beyond the EU: an analysis of wider G20 regulatory action and potential next steps," Journal of Media Law 13 (2021), https://www.scopus.com/record/display.uri?eid=2-s2.0-85101100662\&origin=resultslist \&sort $=$ plf-f \&src $=$ s \&st $1=\& s t 2=\&$ sid $=0216523637$ ab63ccc03b 179735 abd $04 \mathrm{f} \&$ sot $=\mathrm{b} \& \mathrm{sdt}=\mathrm{b} \& \mathrm{sl}=36 \& \mathrm{~s}=\mathrm{TITLE}-\mathrm{ABS}-\mathrm{KEY} \% 28 \mathrm{right}+\mathrm{to}+\mathrm{be}+$ forgotten $\% 29 \& \mathrm{rel}-$ pos $=2 \&$ citeCnt $=0$ \&search Term $=$. 
Data Protection Regulation (GDPR) defines the RTBF as the right "to obtain from the controller the erasure of personal data concerning him or her without undue delay and the controller shall have the obligation to erase personal data without undue delay (European Parliament 2016, p. 43) ${ }^{31}$.

The territorial aspect of the operation of the RTBF deserves special attention, since at present the extension of the right studied in this article relates exclusively to the borders of the European Union, whose court made the initial decision in 2014. This reasoning relies on the idea highlighted by Federico Fabbrini and Edoardo Celeste (2020), whereby the European Union (EU) has been at the forefront of the protection of the right to data protection at the global level. ${ }^{32}$ Thus, as we presume from the Meg Leta Jones' book (2018), two cases addressing the complicated concerns of reputation, identity, privacy, and memory in in the Digital Age were decided the same day on opposite sides of the Atlantic with different conclusions. The $1^{\text {st }}$ - begun in Spain (Google Spain SL, Google Inc. v AEPD, Mario Costeja González) and the $2^{\text {nd }}$ - in the U.S. where two American Idol contestants brought every conceivable claim against Viacom, MTV, and a number of other defendants over online content that led to their disqualification from the television show ${ }^{33}$. I think it is not necessary to waste time detailing the nuances of litigation, because in the context of our research it is important that in formally similar situations judges in Europe and America have made diametrically opposed decisions. Although in the first case we are talking about a historic court verdict that laid the foundation for the application of the RTBF across the EU, in the second case there was a lengthy appeals process for the parties to the proceedings, but we may even give rise to a more antagonistic reading of these two decisions. It would appear, therefore, that under the Federico Fabbrini's endorsements (2020), we now live in a global digital society, which overtakes national boundaries; that is why one's right to data protection may be violated even

31 European Parliament, Regulation (EU) 2016/679 of the European Parliament and of the Council of 27 April 2016 on the protection of natural persons with regard to the processing of personal data and on the free movement of such data, and repealing Directive 95/46, Oficial Journal of the European Union (OJ), 2016, 59(1-88), 294.

32 Fabbrini and Celeste, "The Right to Be Forgotten in the Digital Age," 55.

33 Jones, Ctrl $+Z$ : The Right to Be Forgotten, 11-12. 
where a search engine shows a specific result in a country, which is not that of residence of the data subject concerned ${ }^{34}$.

A few key messages arise from the comparison of depicted challenges in global perspective, where the Ukrainian example, with its unsuccessful legislation and unconditional litigation practice, does not seem to be anything extraordinary at all. According to Cayce Myers (2014), the difference between the European Union and the United States in terms of confidentiality is just one example of the types of difficulties that arise from these new directives. Looking at this struggle for the right to privacy and the RTBF, there are obvious tensions between individuals and corporations, private law practice in the United States and Europe ${ }^{35}$. But at the same time, the worldwide web, has created a more interconnected global dialogue, it has highlighted the legal and mental differences (sometimes similar to a tectonic rift in magnitude) between freedom of speech and self-expression and legal control in common. Nevertheless, we agree with Mattias Goldmann (2020) that, there is little doubt about the plausibility of reading the RTBF decisions as opening a new chapter in judicial dialogue $e^{36}$.

\section{CONCLUSIONS}

The digital transformation of society that is now taking place involves not only the technological development itself, but the improvement of sociolegal scope in common, complicating the process of realization of human rights and their protection in case of violation, contestation or non-recognition. Today's online challenges predetermine the formation of an information culture in which new communicative practices emerge and the old ones are modified.

Furthermore, the last decade in the whole world has become a milestone in the two-stage path of not only the Ukrainian, but also the entire European legal thought, which finally outlined the transition from nor-

34 Fabbrini and Celeste, "The Right to Be Forgotten in the Digital Age," 64.

35 Myers, "Digital Immortality vs. "The Right to be Forgotten"," 59.

36 Goldmann, "As Darkness Deepens," 46. 
mative to interpretive law enforcement. The emergence and development of systematic application of the RTBF in the activities of all legal institutions without exception was a crucial prerequisite, a factor that accelerated the evolution of the entrenchment of this right in Ukraine from latent manifestations in comparative legal studies to its compartmentalization into a separate ecosystem of law enforcement activity with its own socio-ideological and judicial criteria, as well as the appearance of an increasing number of court decisions, aimed at the implementation of the components of this right in practice.

\section{REFERENCES}

Adams Shoor, Emily. "Narrowing the Right to Be Forgotten: Why the European Union Needs to Amend the Proposed Data Protection Regulation." Brooklyn Journal of International Law 39 (2014): 487-521.

Daskal, Jennifer. "Google, Inc v. Equustek Solutions." American Journal of International Law 112, Issue 4 (2018): 727-733.

Erdos, David. "The right to be forgotten' beyond the EU: an analysis of wider G20 regulatory action and potential next steps." Journal of Media Law 13 (2021): 18-30.

Fabbrini, Federico, and Edoardo Celeste. "The Right to Be Forgotten in the Digital Age: The Challenges of Data Protection Beyond Borders." German Law Journal 21 (2020): 55-65.

Globocnik, Jure. "The Right to Be Forgotten is Taking Shape: CJEU Judgments in GC and Others (C-136/17) and Google v CNIL (C-507/17)." GRUR International 69(4) (2020): 380-388.

Goldmann, Mattias. "As Darkness Deepens: The Right to be Forgotten in the Context of Authoritarian Constitutionalism." German Law Journal 21 (2020): 45-54.

Kwak, Chanhee, Lee Junyeong, and Lee Heeseok. "Could You Ever Forget Me? Why People Want to be Forgotten Online." Journal of Business Ethics 168, Issue 5 (2021): 3-21.

Machowicz, Kinga. "Observance of human rights as an element of shaping the position of the European enterprise in the knowledge-based economy." Review of European and Comparative Law 44, no. 1 (2021): 7-18.

Mayer-Schönberger, Viktor. Delete: The virtue of forgetting in the digital age. Princeton: Princeton University Press, 2011. 
Myers, Cayce. "Digital Immortality vs. "The Right to be Forgotten": A Comparison of U.S. and E.U. Laws Concerning Social Media Privacy." Revista Română de Comunicare şi Relaţii Publice, no. 3XVI (2014): 47-60.

Jankélévitch, Vladimir. Forgiveness. Chicago: University of Chicago Press, 2005.

Jones, Meg Leta. Ctrl + Z: The Right to Be Forgotten. New York: New York University Press, 2018.

Kuner, Christopher. "The Court of Justice of the EU Judgment on Data Protection and Internet Search Engines." LSE Law, Society and Economy Working Papers 3 (2015). https://papers.ssrn.com/sol3/papers.cfm?abstract_ id=2496060. Accessed March 27, 2021.

Larsen, Rebekah. "Mapping Right to be Forgotten frames: Reflexivity and empirical payoffs at the intersection of network discourse and mixed network methods." New media \& society 22(7) (2020): 1245-1265.

Pagallo, Ugo, and Massimo Durante. "Legal Memories and the Right to be Forgotten." In Protection of Information and the Right to Privacy - A New Equilibrium?, edited by Luciano Floridi, 144. Oxford: Springer, 2014.

Rosen, Jeffrey. "The Right to Be Forgotten." Stanford Law Review, Symposium Issue (2012): 88-95.

Tabaszewski, Robert. "The Permissibility of Limiting Rights and Freedoms in the European and National Legal System due to the Health Protection." Review of European and Comparative Law 42, no. 3 (2020): 51-89.

Uncular, Selen. "The right to removal in the time of post-Google Spain: myth or reality under general data protection regulation?." International Review of Law, Computers \& Technology 33 (3) (2019): 309-329.

Wulff, Carsten M. "The Right to be Forgotten in Post-Google Spain Case Law: an Example of Legal Interpretivism in Action?." Comparative Law Review 26 (2020): 255-279. 